\title{
SIMULATION OF SYNCHRONIZATION OF NONLINEAR OSCILLATORS BY THE EXTERNAL FIELD
}

\author{
V.M. Kuklin, D.N. Litvinov, S.M. Sevidov, A.E. Sporov \\ V.N. Karazin Kharkiv National University, School of Computer Sciences \\ Svobody Sq. 4, 61022, Kharkiv, Ukraine \\ e-mail:sporov@yahoo.com \\ Received March 17, 2017
}

In this paper, the self-consistent model was considered, consisting of a system of oscillators, the coupling between them was assumed to be integral (due to the fields formed as a result of their co-radiation). With the help of this model, the features of synchronization by waves of finite amplitude of a system of oscillators were refined, the initial phase values of which are random. The effect of nonlinearity, in particular, due to the change in the mass of the oscillator due to relativistic effects, was taken into account. It was shown that the nonlinearity does not violate the nature of the energy exchange between the wave and the oscillator system, leading only to a slight decrease in the efficiency of such an exchange.

KEYWORDS: oscillator, nonlinearity, synchronization, energy exchange

\section{МОДЕЛЮВАННЯ ПРОЦЕСІВ СИНХРОНІЗАЦІЇ СИСТЕМИ НЕЛІНІЙНИХ ОСЦИЛЯТОРІВ ЗОВНІШНІМ ПОЛЕМ}

В.М. Куклін, Д.М. Літвінов, С.М. Севідов, О.Є. Споров

Харківський національний університет імені В.Н. Каразіна факультет комп'ютерних наук м. Свободи 4, 61022, Харків, Україна

У даній роботі було розглянуто самоузгоджену модель, що складається з системи осциляторів зв'язок між якими передбачався як інтегральний (за рахунок полів, що формуються в результаті їх спільного випромінювання). За допомогою даної моделі було уточнено особливості синхронізації хвилями скінченої амплітуди системи осциляторів, початкові значення фаз яких $є$ випадковими. Було проведено облік впливу нелінійності, зокрема, обумовленої зміною маси осцилятора за рахунок релятивістських ефектів. Було показано, що урахування нелінійності не порушує характер обміну енергією між хвилею і системою осциляторів, приводячи лише до невеликого зниження ефективності такого обміну.

КЛЮЧОВІ СЛОВА: осцилятор, нелінійність, синхронізація, обмін енергією

\section{МОДЕЛИРОВАНИЕ ПРОЦЕССОВ СИНХРОНИЗАЦИИ СИСТЕМЫ НЕЛИНЕЙНЫХ ОСЦИЛЛЯТОРОВ ВНЕШНИМ ПОЛЕМ \\ В.М. Куклин, Д.Н. Литвинов, С.М. Севидов, А.Е Споров \\ Харьковский национальный университет имени В. Н. Каразина факультет компьютерных наук пл. Свободы 4, 61022, Харьков, Украина}

В данной работе была рассмотрена самосогласованная модель, состоящая из системы осцилляторов, связь между которыми предполагалась интегральной (за счет полей, формируемых в результате их совместного излучения). С помощью данной модели были уточнены особенности синхронизации волнами конечной амплитуды системы осцилляторов, начальные значения фаз которых являются случайными. Был проведен учет влияния нелинейности, в частности, обусловленной изменением массы осциллятора за счет релятивистских эффектов. Было показано, что нелинейность не нарушает характер обмена энергией между волной и системой осцилляторов, приводя лишь к небольшому снижению эффективности такого обмена.

КЛЮЧЕВЫЕ СЛОВА: осциллятор, нелинейность, синхронизация, обмен энергией

Synchronization of systems of oscillators which drew the attention of C. Huygens as early as in the seventeenth century, was discussed by many researchers [1,2]. The influence of external periodic force is able to adjust the parameters of the oscillator and its phase. Therefore, synchronization is often referred to as "locking" of frequency and/or phase $[3,4]$.

The most efficient synchronization of a large number of oscillators occurs under the influence of a strong external force or under the impact of already synchronized oscillators.

The coupling between the oscillators can be local due to their mutual non-linear influence or have integral nature due to the fields generated by their joint radiation. Of great interest are the various parametric mechanisms affecting the efficiency of interaction of oscillators [5,6], although in this work, we neglect their direct interaction. Instead, we focus on the case when independent oscillators interact via the common field (generated by them and influencing them).

An important factor of interest to this case is the apparent self-consistency of the described systems and the great practical importance of such problems. The considered models are able to clarify some useful properties of oscillators' synchronization by the finite-amplitude waves when initial phases of oscillators are random. Also, we studied nonlinear effects, particularly caused by the change of the oscillator's mass due to the relativity effects.

So, the aim of the work is to investigate the features of synchronization by waves of finite amplitude of the specified oscillator system taking into account the nonlinear effects. It is shown that nonlinearity does not introduce any (C) Kuklin V.M., Litvinov D.N., Sevidov S.M., Sporov A.E., 2017 
new effects into the nature of energy exchange between the wave and oscillators in the regime of synchronization by a large field, and only leads to a moderate decrease of the efficiency of such exchange.

PROBLEM STATEMENT

Consider the synchronization of the oscillators by the electromagnetic wave with frequency $\omega$, wave vector $\vec{k}=(0,0, k)$, and the fields of the form: $\vec{E}=(E, 0,0), \vec{B}=(0, E, 0)$, and $E=|E| \cdot \exp \{-i \omega t+i k z+i \varphi\} . N$ oscillators are distributed along the $O Z$ axis over the wavelength $2 \pi / k$. The mass of the oscillator is equal $m$, the charge is equal $-e$, the frequency of the oscillator coincides with the frequency of the wave $\omega$. The initial oscillation amplitude of the oscillator is $a_{0}$. We assume that the oscillator moves only in the direction of the axis $O X$. In this case, the influence of the magnetic field of the wave on the dynamics of the oscillator can be neglected. Amplitude of their oscillations as a function of time is equal to $x_{i}=\left|x_{i}\right| \cdot \exp \left\{-i \omega t+i \psi_{i}\right\}$. The equations for the field, in this case, can be represented as:

$$
\begin{aligned}
& \frac{\partial \mathrm{E}}{\partial \tau}=\frac{1}{2 N} \sum_{i=1}^{N} A_{i} \cdot \operatorname{Sin}\left(\psi_{i}-Z_{i}-\varphi\right), \\
& \mathrm{E} \frac{\partial \varphi}{\partial \tau}=-\frac{1}{2 N} \sum_{i=1}^{N} A_{i} \cdot \operatorname{Cos}\left(\psi_{i}-Z_{i}-\varphi\right) .
\end{aligned}
$$

The motion equations for the oscillators will be:

$$
\begin{aligned}
& \frac{\partial A_{i}}{\partial \tau}=\frac{\mathrm{E}}{2} \operatorname{Sin}\left(\varphi-\psi_{i}+Z_{i}\right), \\
& \frac{\partial \psi_{i}}{\partial \tau}-\Delta_{i}=-\frac{\mathrm{E}}{2 A_{i}} \operatorname{Cos}\left(\varphi-\psi_{i}+Z_{i}\right) .
\end{aligned}
$$

The energy conservation law follows from the equations (1) and (3)

$$
\mathrm{E}^{2}+\frac{1}{N} \sum_{i=1}^{N} A_{i}^{2}=\text { const }
$$

where we have used the following representations:

$$
\begin{gathered}
\frac{e E}{\omega m \gamma a_{0}}=\mathrm{E}, \tau=\gamma t, A_{i}=\left|x_{i}\right| / a_{0}, \\
\gamma^{2}=\frac{\pi e^{2} n_{0}}{\varepsilon_{0} m}, k z_{i}=Z_{i} \subset(0,2 \pi) .
\end{gathered}
$$

For the non-relativistic case (the mass of the oscillator is independent of its speed) assume that $\Delta_{i}=0$, with relativity: $\Delta_{i}=\alpha \cdot A_{i}^{2}, \alpha=\frac{3 \omega}{4}\left(k \cdot a_{0}\right)^{2}$.

\section{ANALYSIS OF DIFFERENT MODES OF OPERATION}

Pendulum mode

In the case when the mass of the oscillators in the lab frame is independent of their speed or their energy $\left(\Delta_{i}=0\right)$, for the high initial energy of field and particles $\left(\mathrm{E}(0)=A_{i}(0)=1\right)$ we can see the following dynamics of the system.

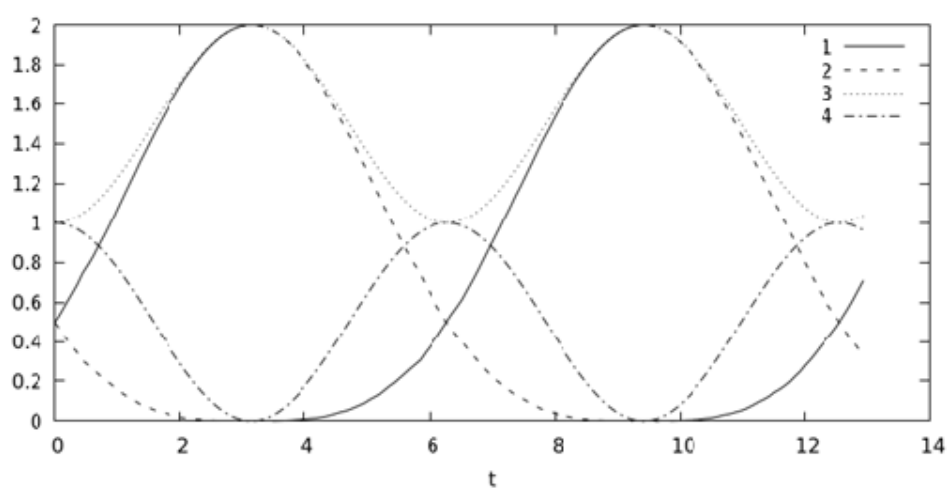

Fig. 1. Dynamics of energy redistribution in the system 
Fig. 1 depicts the energy of the emitting particles with a solid line, and the energy of absorbing particles with the dashed line (i. e., energy is taken from the wave). Dotted curve represents total energy of all particles. The dash-dotted curve depicts the field's energy $\mathrm{E}^{2}$ (i.e., the last two curves are components of integral (5)). Fig.2 shows how many particles absorb or emit energy.

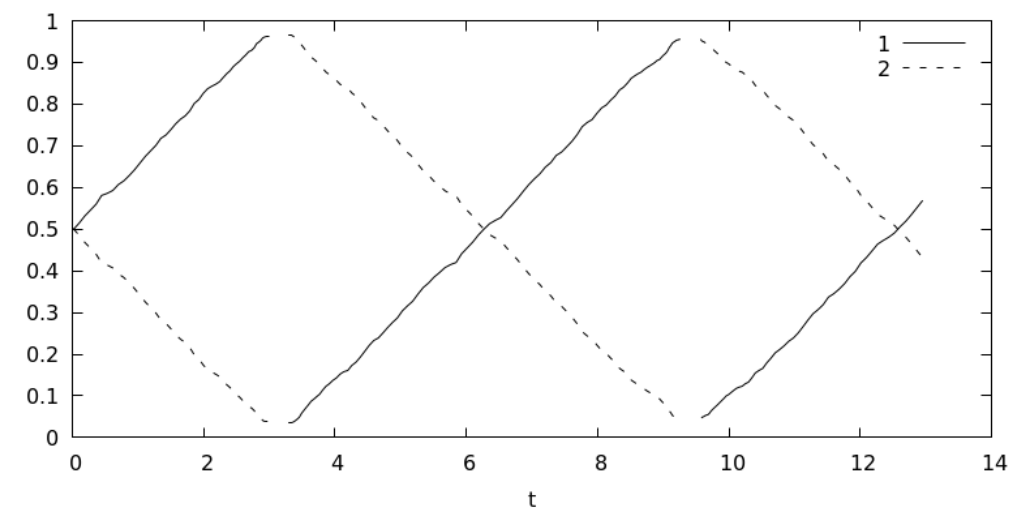

Fig. 2. The number of radiating (solid curves) and absorbing particles (dotted curves)

The distribution of amplitudes of particle oscillations and their phases for several time moments is shown in Fig. 3.

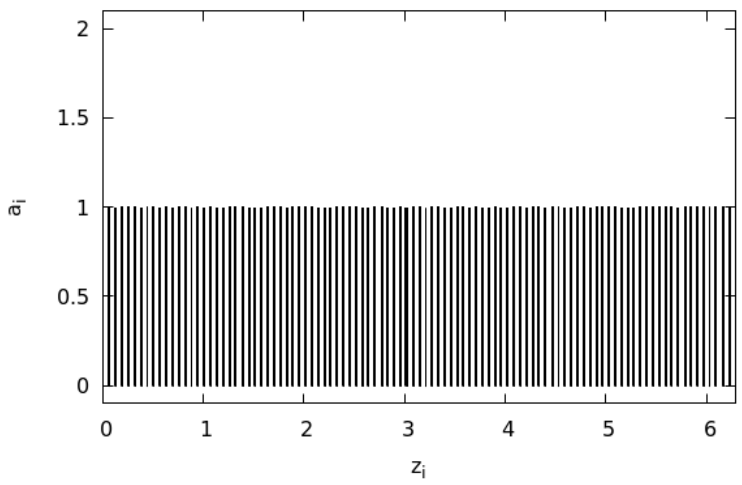

$\mathrm{t}=0$

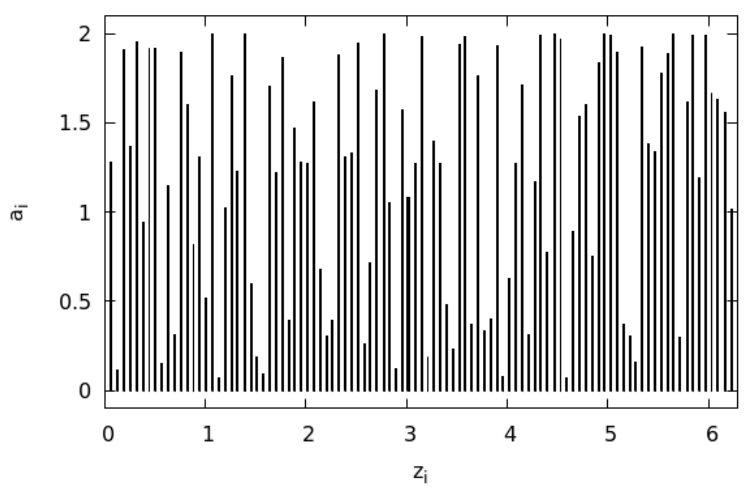

$\mathrm{t}=3-0$

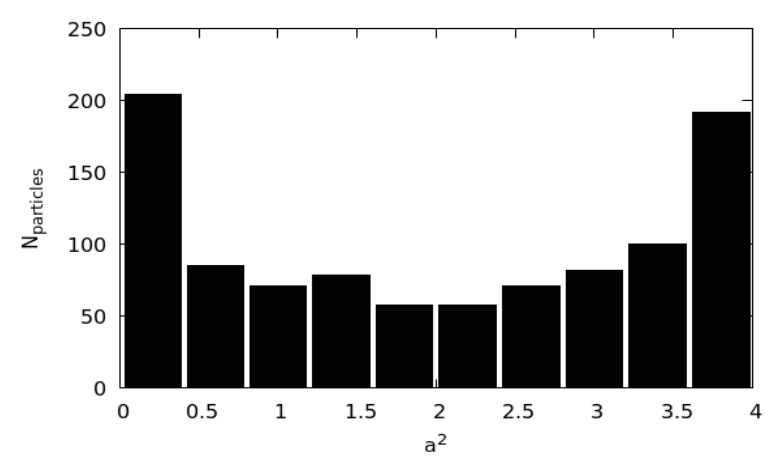

$\mathrm{t}=3+0$

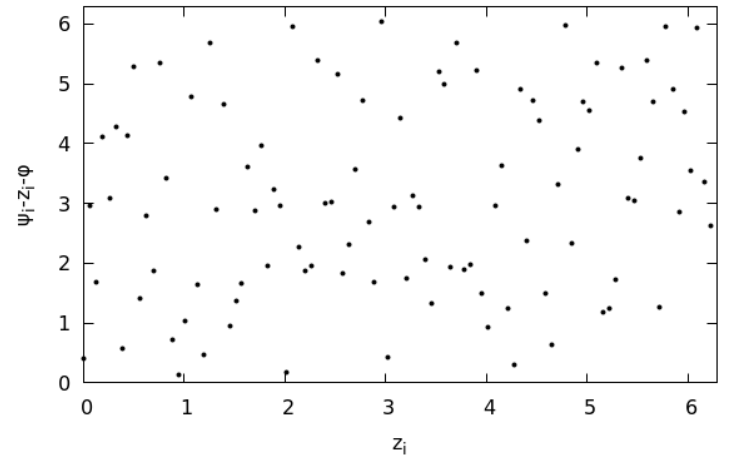

$\mathrm{t}=0$

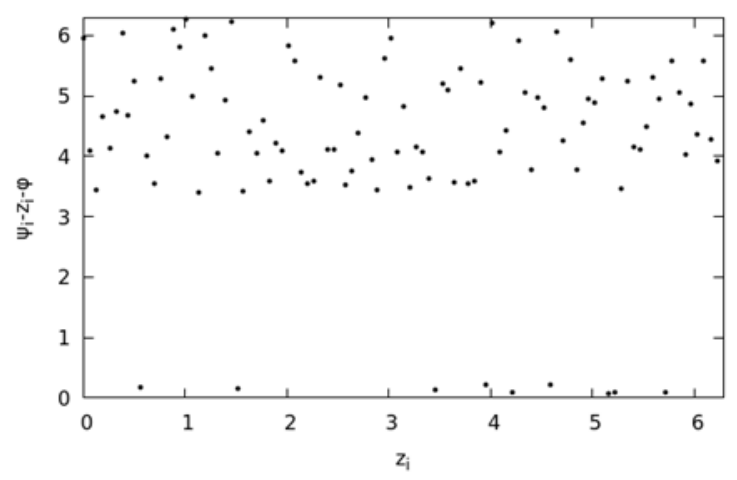

$\mathrm{t}=3-0$

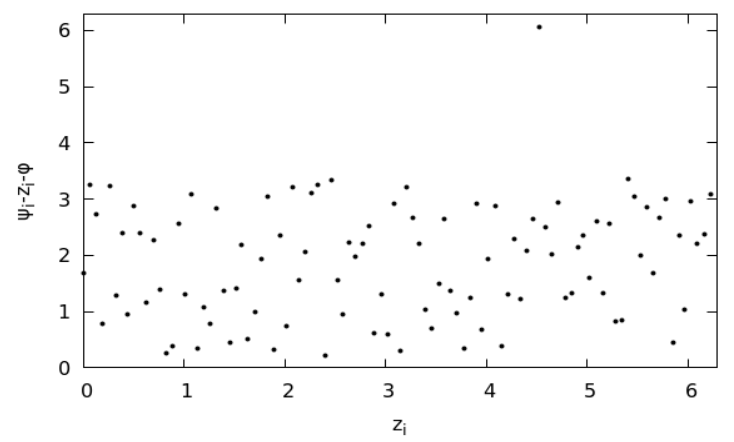

$\mathrm{t}=3+0$ 


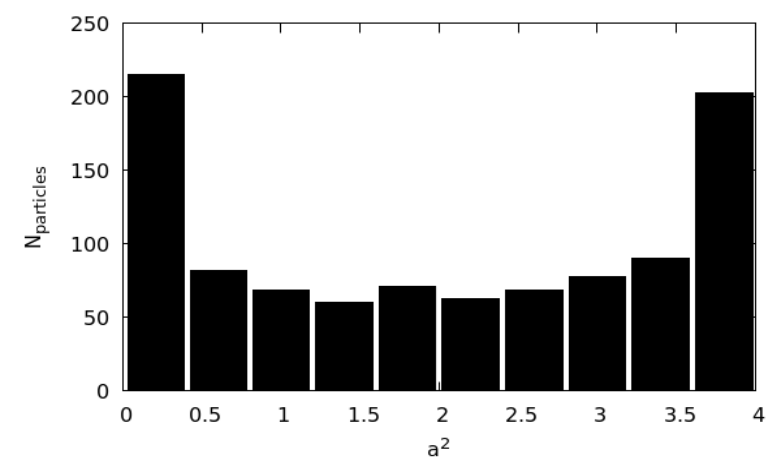

$\mathrm{t}=9-0$

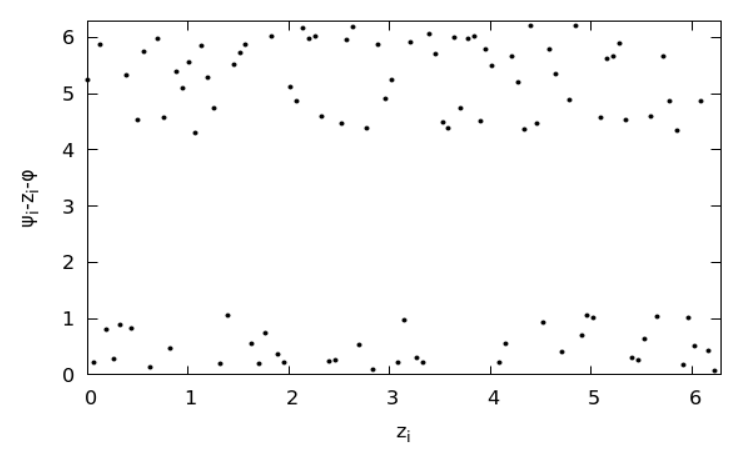

$\mathrm{t}=9-0$

Fig. 3. Amplitude (left) and phase (right) oscillators at different moments of time

At the initial moment, the amplitudes of all oscillators are almost the same, and the phases are randomly distributed. When reaching field minimum ( $\mathrm{t}=3-0)$ we get so-called "soft lock" of the oscillators' phases (phase differences $\Phi_{i}=\psi_{i}-Z_{i}-\varphi$ of the oscillators are different, but nevertheless, their variation is limited, $\pi<\Phi_{i}<2 \pi$ ). Until reaching the minimum of the field, all oscillators are in the phase of absorption. Later (at $\mathrm{t}=9$ ) a small part of the oscillators leaves the zone of phase lock. Because of the small value of field amplitude at $\mathrm{t}=3$ и $\mathrm{t}=9$, the derivatives $\frac{\partial \varphi}{\partial \tau}$ grow rapidly, and the phase of the field changes by $\pi$. After phase jump, oscillators move into the radiation area $0<\Phi_{i}<\pi$. The distribution of the amplitudes of the oscillators is presented for times $\mathrm{t}=3+0$ and $\mathrm{t}=9-0$. As can be seen, the amplitude of the oscillations varies greatly. The phase plane (in polar coordinates) with the oscillators looks like the following (Fig.4).
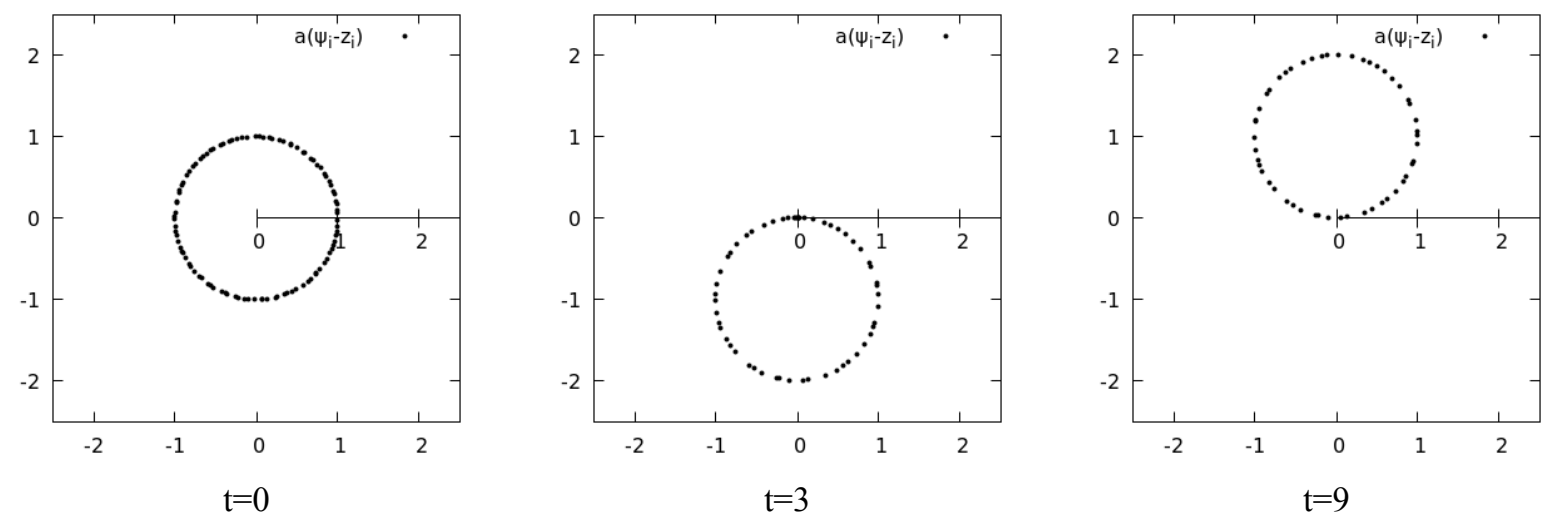

Fig. 4. The behavior of the oscillators in the phase plane at different points in time

From this figure, we can observe that the particles do not move relative to each other as the system evolves. Instead, they synchronously move (sometimes with rotation) on the plane $\left(A_{i} \cos \left(\psi_{i}-Z_{i}-\phi\right) ; A_{i} \sin \left(\psi_{i}-Z_{i}-\phi\right)\right)$. To prove this, express the Cartesian coordinates of particles on that plane through their polar coordinates in the phase space:

$$
\begin{aligned}
& x_{i}=A_{i} \cos \left(\psi_{i}-Z_{i}-\phi\right) . \\
& y_{i}=A_{i} \sin \left(\psi_{i}-Z_{i}-\phi\right) .
\end{aligned}
$$

After taking derivatives and simple algebraic transformations we get:

$$
\begin{gathered}
\frac{\partial x_{i}}{\partial t}=y_{i} \frac{\partial \phi}{\partial t} \\
\frac{\partial y_{i}}{\partial t}=-\frac{E}{2}-x_{i} \frac{\partial \phi}{\partial t} .
\end{gathered}
$$

From these equations, it is seen that the particle motion is a combination of two components: translation along the $\mathrm{y}$-axis at a speed proportional to the amplitude of the field $\mathrm{E}$, and rotation around the origin by the angle proportional to the field phase $\varphi$. With respect to each other the particles do not move, which follows from equality to zero of the derivative of the distance between a pair of arbitrary particles 1 and 2: 


$$
\frac{1}{2} \frac{\partial}{\partial t}\left(\left(x_{1}-x_{2}\right)^{2}+\left(y_{1}-y_{2}\right)^{2}\right)=\left(x_{1}-x_{2}\right)\left(y_{1}-y_{2}\right) \frac{\partial \phi}{\partial t}+\left(y_{1}-y_{2}\right)\left(-x_{1}+x_{2}\right) \frac{\partial \phi}{\partial t}=0 .
$$

Changing the initial conditions, the system behavior may differ significantly.

\section{Generation mode}

Let the mass of the oscillators in the laboratory frame of reference still does not depend on their speed or their energy $\left(\Delta_{i}=0\right)$. Consider the case $\mathrm{E}(0)=0.1 ; A_{i}(0)=1$. In this case, the wave of small amplitude is unable to synchronize the oscillators, as seen in Fig. 5 and Fig. 6.

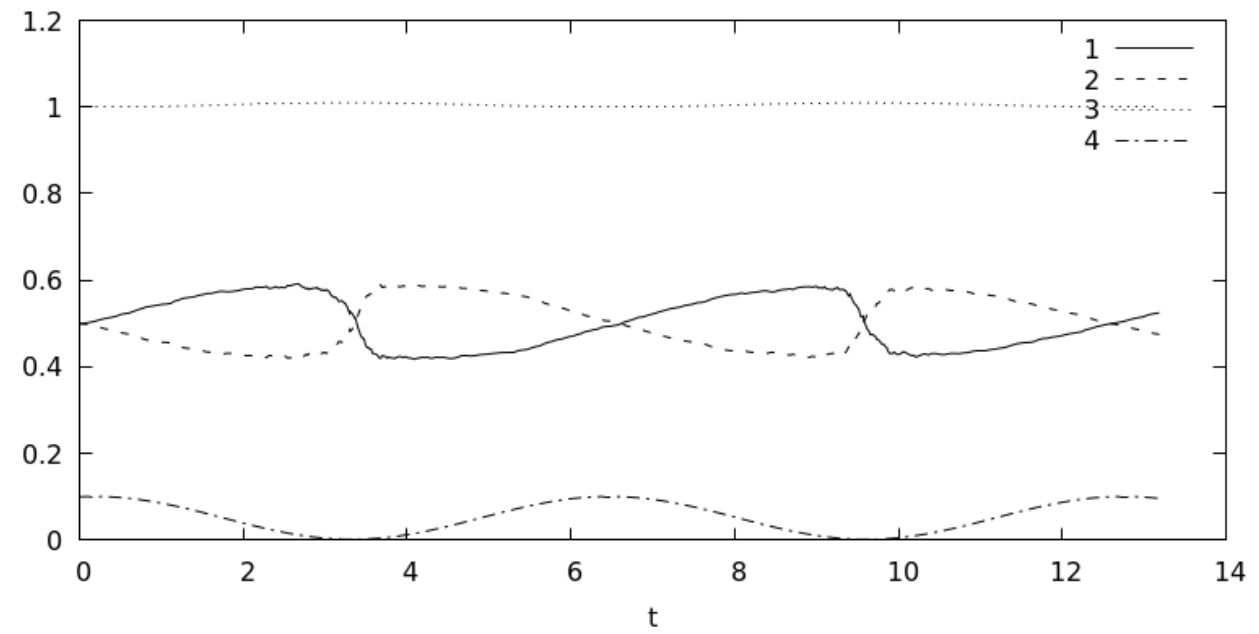

Fig. 5. Generation mode. 1 - energy of emitting particles, 2 - energy of absorbing particles, 3 - energy of all particles, 4 - field energy

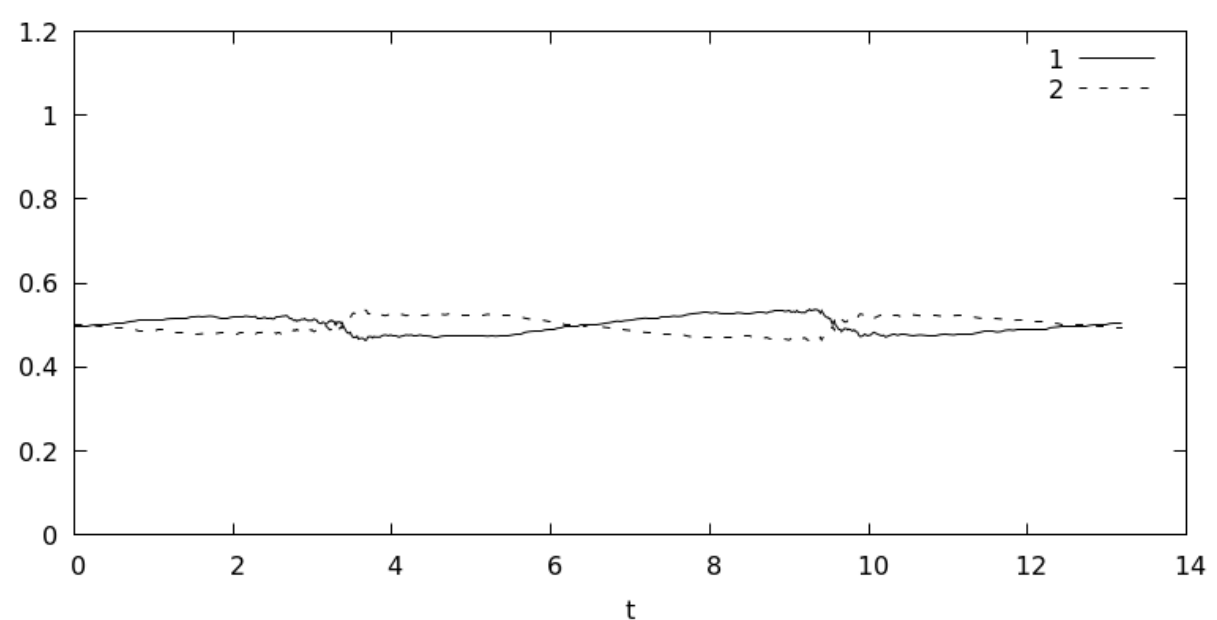

Fig. 6. Generation mode. The number of emitting (solid curves) and absorbing (dotted curves) particles

The "ring" of particles which at the initial moment is the same as in Fig. 4, at $\mathrm{t}=0$ slightly deviates from its initial position.

\section{Strong synchronization mode}

When $\mathrm{E}(0)=1 ; A_{i}(0)=0.1$, on the contrary, the field synchronizes oscillators much better. For these initial values, we have the following system dynamics (Figs. 7,8).

At the initial time moment, all the amplitudes are small and almost the same, and the phases are distributed randomly (Fig.9).

When reaching the minimum of the field $(\mathrm{t}=3-0)$ a tough lock of the phases of the oscillators occurs (phase difference $\Phi_{i}=\psi_{i}-Z_{i}-\varphi$ of the oscillators varies, but the variation is minimal, and all of $\Phi_{i} \approx 5$ ). Until reaching of the minimum of the field, all oscillators are in the phase of effective absorption. Because of the smallness of the amplitude of the field around the time point $\mathrm{t}=3$ and $\mathrm{t}=9$ derivatives $\frac{\partial \varphi}{\partial \tau}$ experience jumps, and the phase of the field 
changes by $\pi$. After the jump, oscillators are moving into the radiation area where $\Phi_{i} \approx 1.2$. Note that in this case, the phase lock is effective and the oscillators were all the time within the area of the phase lock.

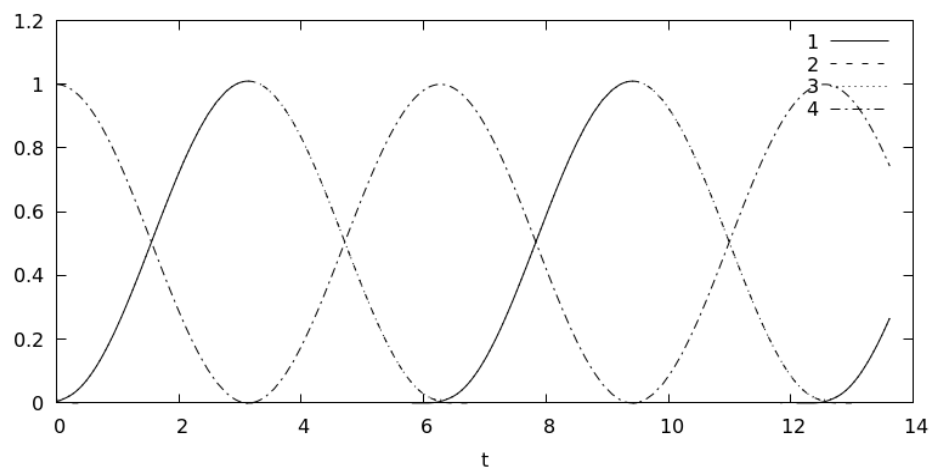

Fig. 7. Strong synchronization mode

1 - energy of emitting particles, 2 - energy of absorbing particles, 3 - energy of all particles 4 - field energy

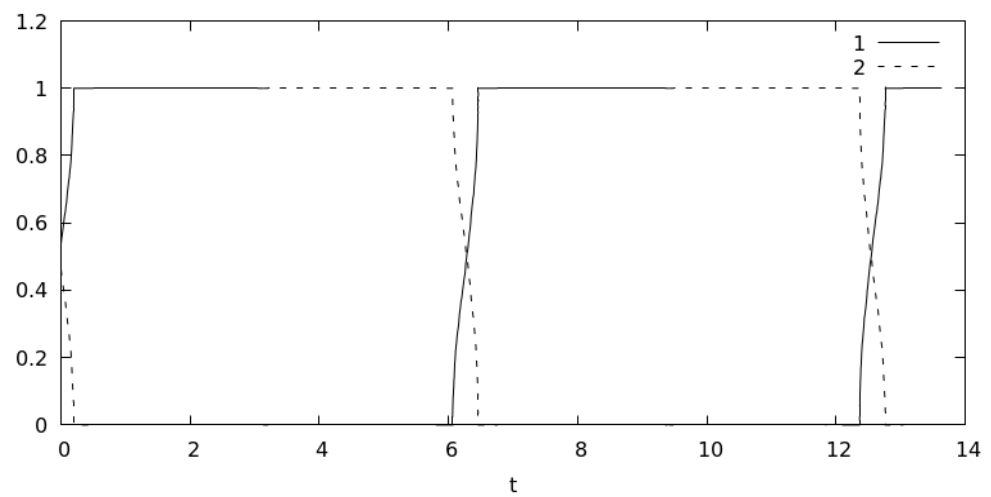

Fig. 8 Strong synchronization mode.

The number of emitting (solid curves) and absorbing (dotted curves) particles

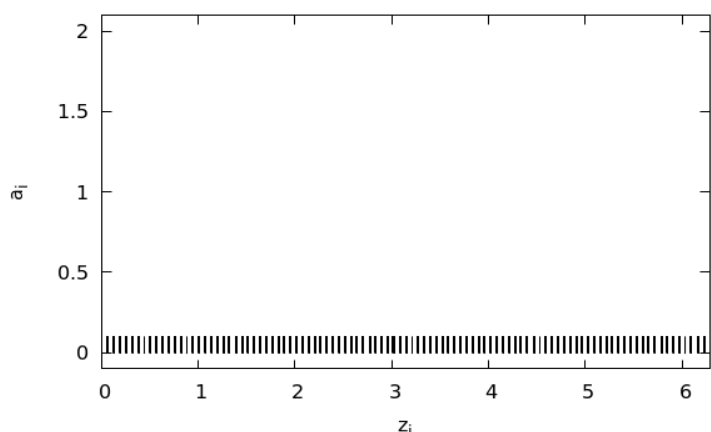

$\mathrm{t}=0$

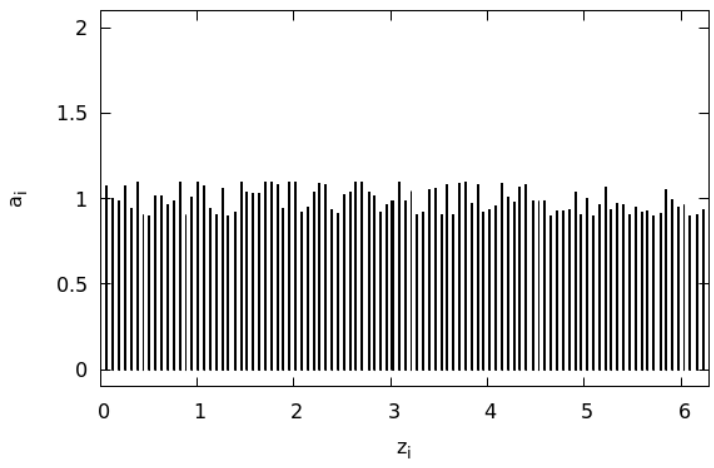

$\mathrm{t}=3-0$

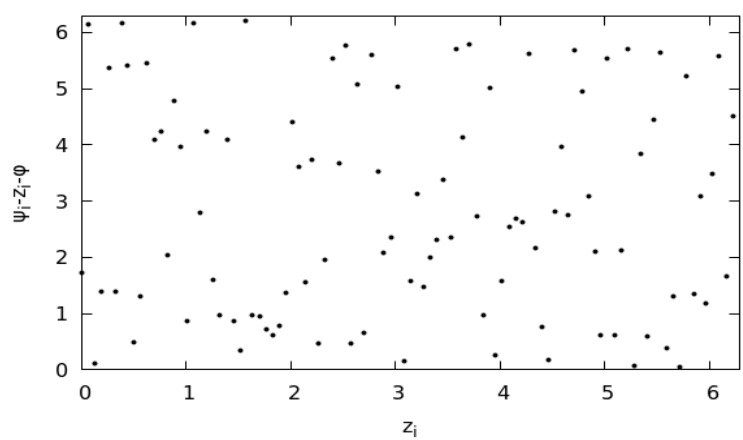

$\mathrm{t}=0$

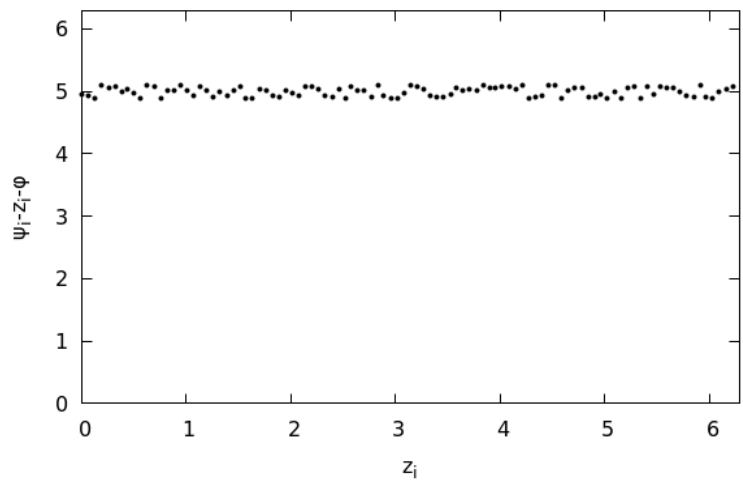

$t=3-0$ 

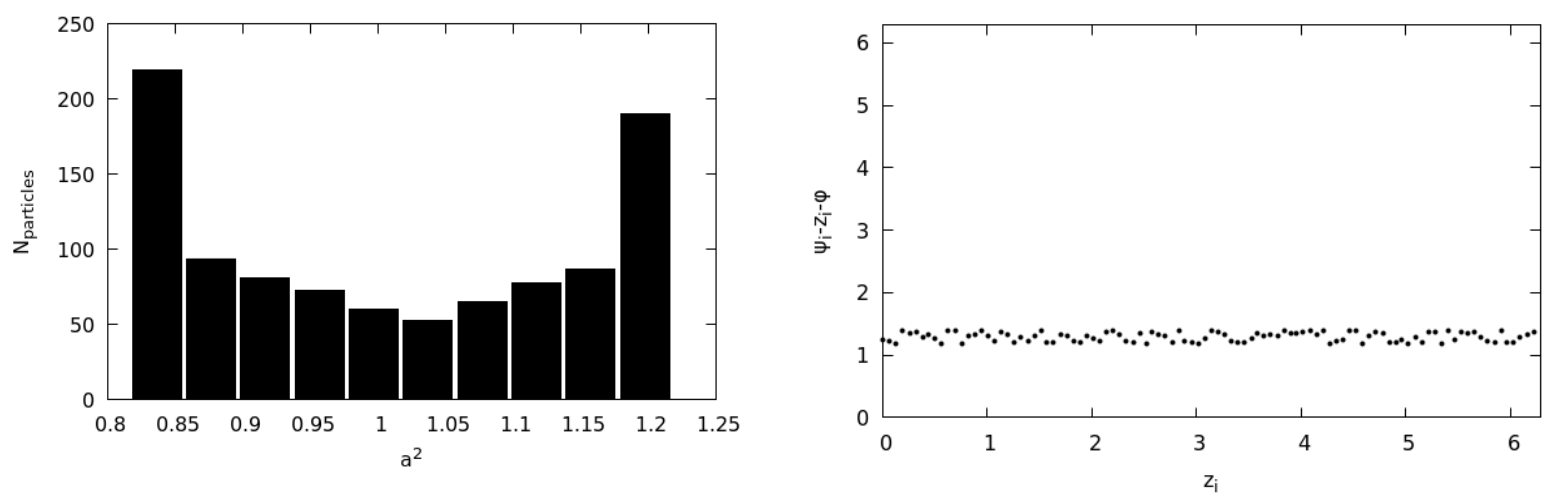

$\mathrm{t}=3+0$
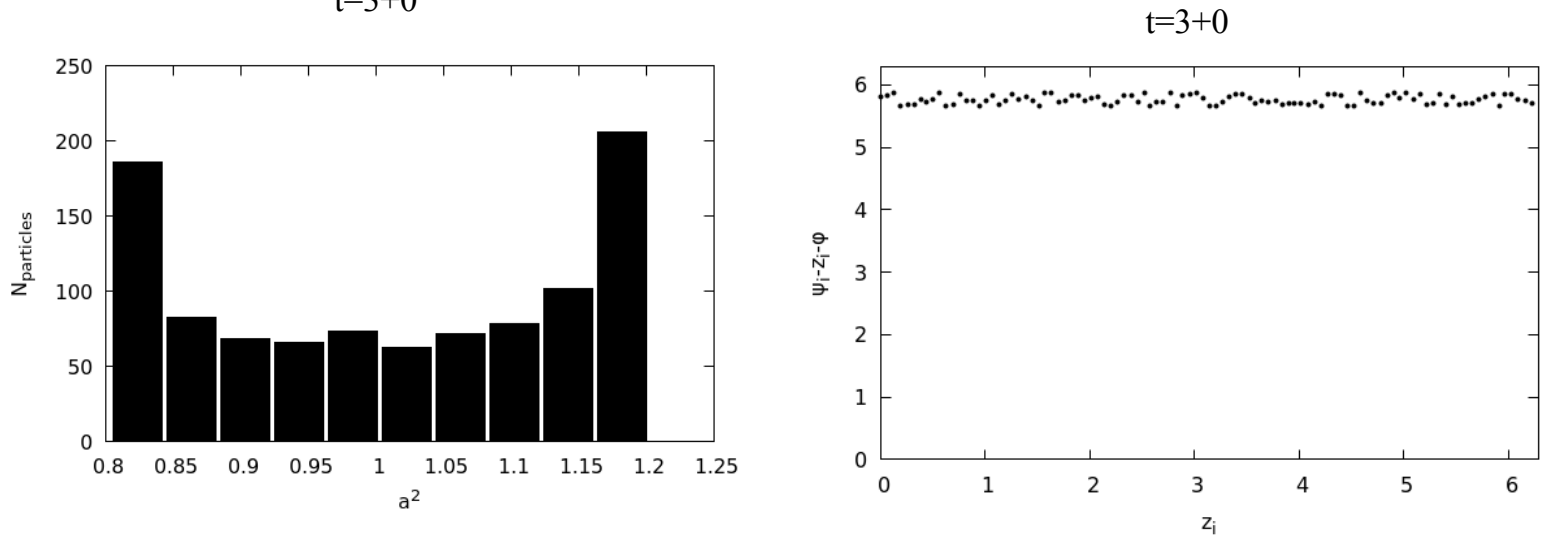

$\mathrm{t}=9-0$

$\mathrm{t}=9-0$

Fig. 9. The regime of strong synchronization. Amplitude (left) and phase (right) oscillators at different points in time

The distributions of the amplitudes of the oscillators are presented for times $t=3+0$ and $t=9-0$. It can be seen that the interval of change of the oscillation amplitude, in this case, is significantly narrowed.

The placement of the oscillators on the phase plane looks like the following (Fig. 10).
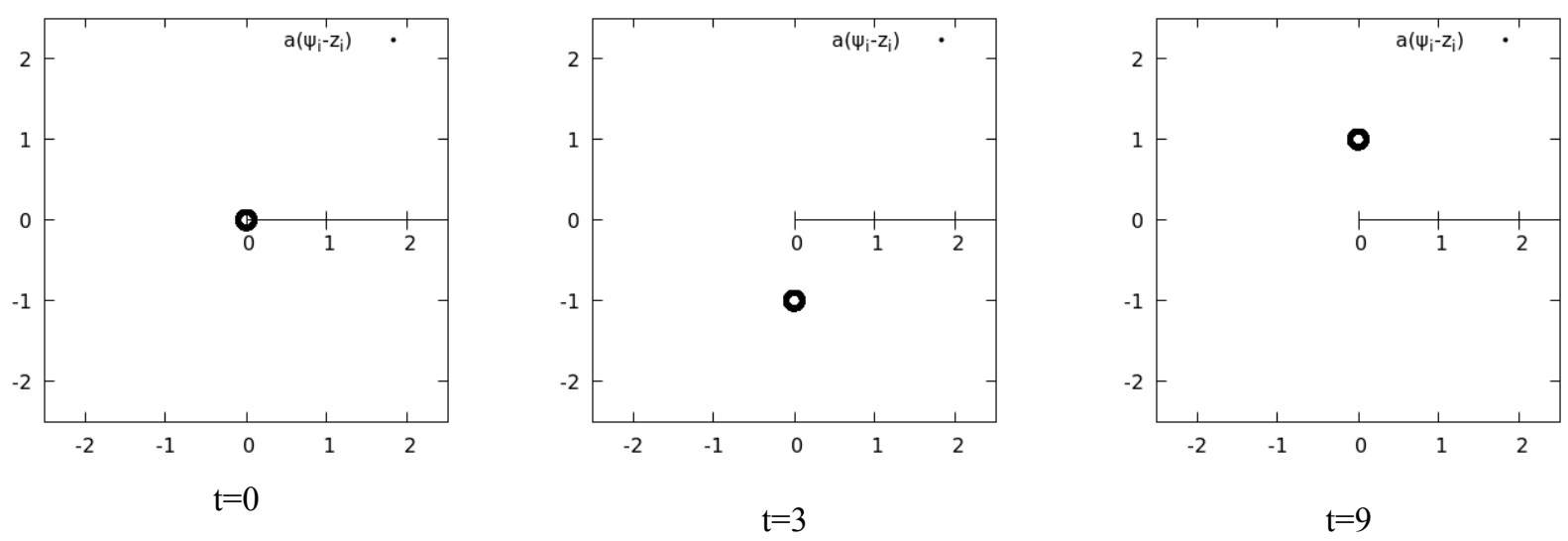

Fig. 10. The regime of strong synchronization. The behavior of the oscillators in the phase plane at different points in time

THE NON-LINEARITY

The statement that in the regime of synchronization by a large field the nonlinearity of the oscillators significantly distorts the dynamics of the system is greatly exaggerated (Although, it should be noted, that in the field generation regime, the influence of nonlinearity is important [7]). To show this, we introduce the effect of the oscillator's mass change in the laboratory frame by assuming, $\alpha$ (in equation 4). Consider the case when $\alpha=0.3$. It can be shown that in the generating mode the results are slightly different from the linear case when $\alpha=0$. Therefore, we focus on the case of strong synchronization. When $\mathrm{E}(0)=1 ; A_{i}(0)=0.1$, the field still strongly synchronizes the oscillators (Figs. 11,12). 


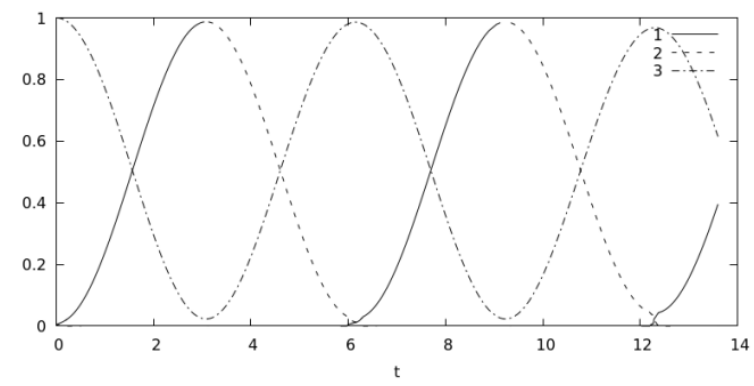

Fig. 11. The regime of strong synchronization of nonlinear oscillators. 1 - energy emitting particles, 2 - energy absorbing particles, 3 - energy of all particles, 4 - field energy.

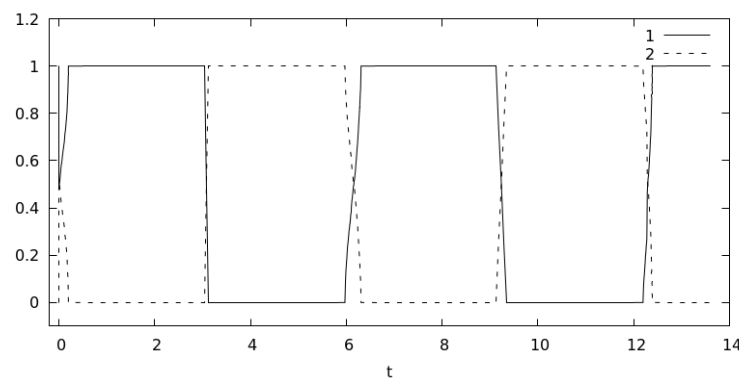

Fig. 12. The regime of strong synchronization of nonlinear oscillators. The number of radiating (solid curves) and absorbing particles (dotted curves)

The initial state is similar to the case of strong synchronization where $\alpha=0$. Further dynamics is different from the linear case. First of all, the wave's phase jump due to the phase mismatch of the oscillators and not so significant decrease in the amplitude of the field in the minimum is not so sharp (Fig. 11). Therefore, the locked phases of the oscillators smoothly transit from the region of absorption to the region of the radiation. The average value of the phases at $\mathrm{t}=3$ was approximately $\left\langle\Phi_{i}\right\rangle \approx \pi$. At the maximum of the field, capture conditions are violated and we can see the differentiation of the oscillators in two groups. However, later we observe a strong enough phase lock (Fig 13). It is less effective than in the linear case, but still very significant.

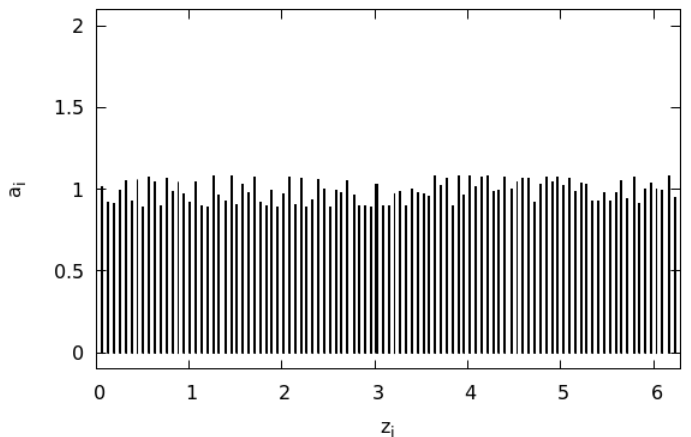

$\mathrm{t}=3$

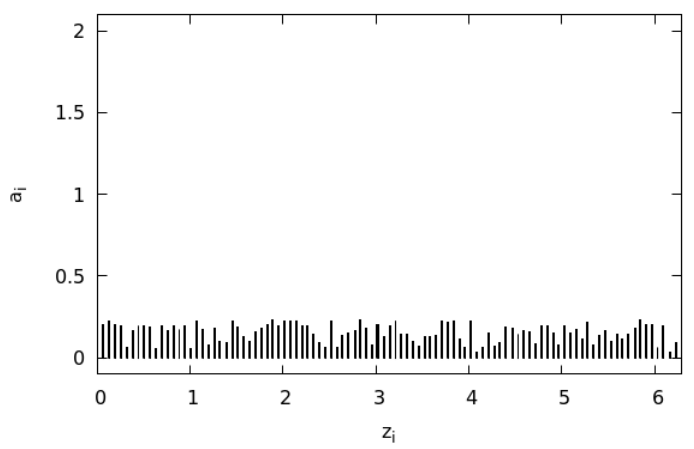

$\mathrm{t}=6$

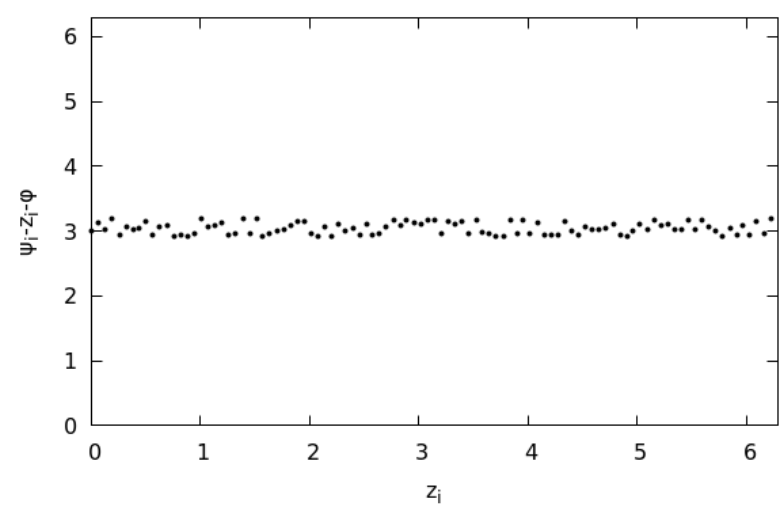

$\mathrm{t}=3$

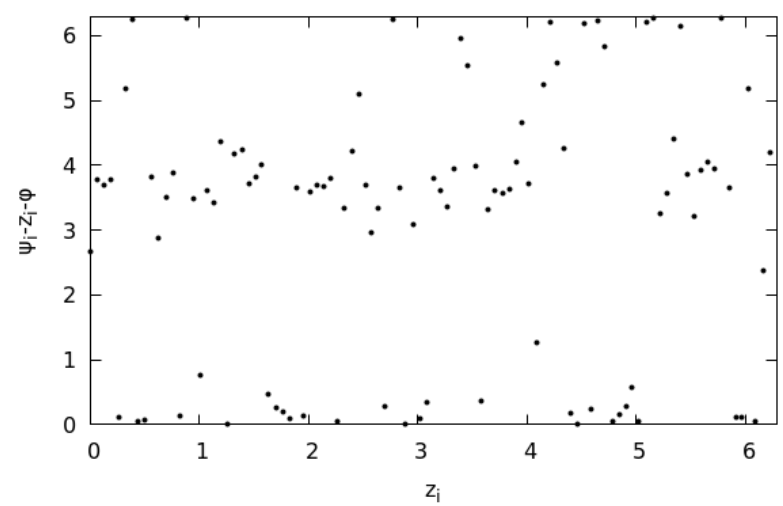

$\mathrm{t}=6$ 


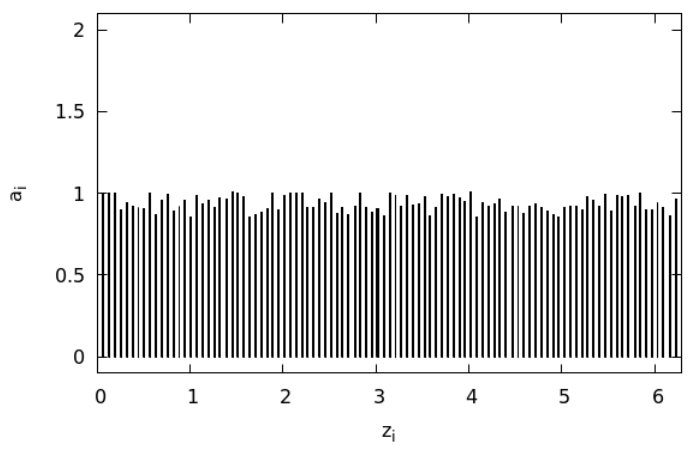

$\mathrm{t}=9-0$

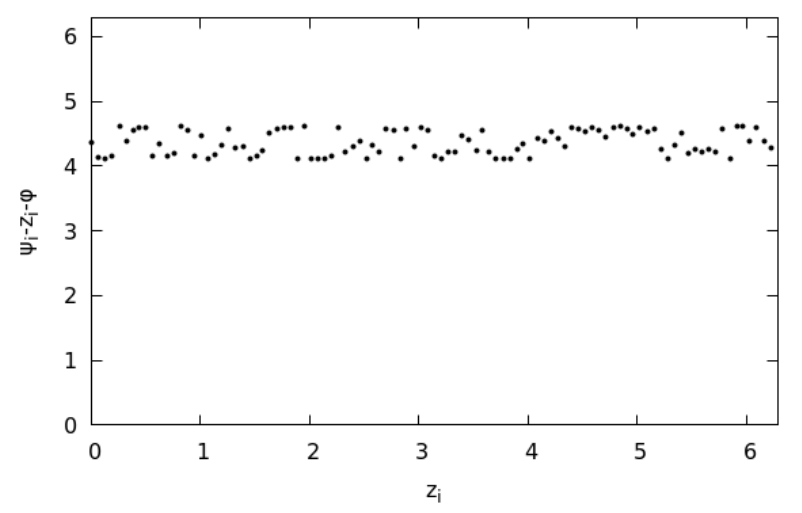

$\mathrm{t}=9-0$

Fig.13. The regime of strong synchronization of nonlinear oscillators.

Amplitude (left) and phase (right) oscillators at different points in time

The placement of the oscillators on the phase plane can be represented in the form, presented on Fig. 14.

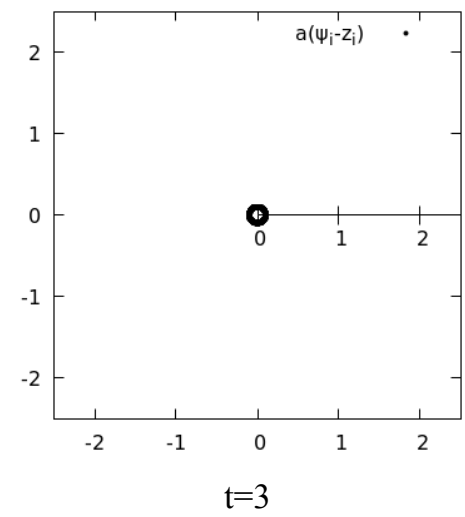

$\mathrm{t}=3$

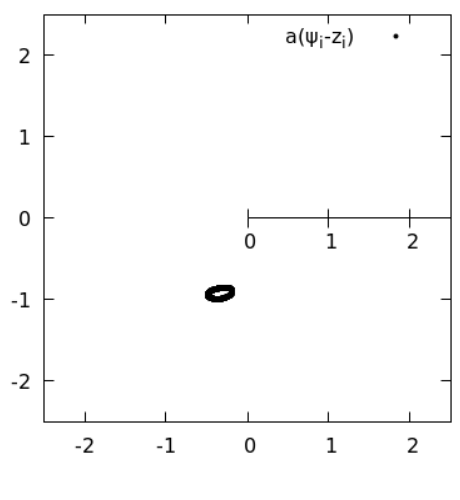

$\mathrm{t}=6$

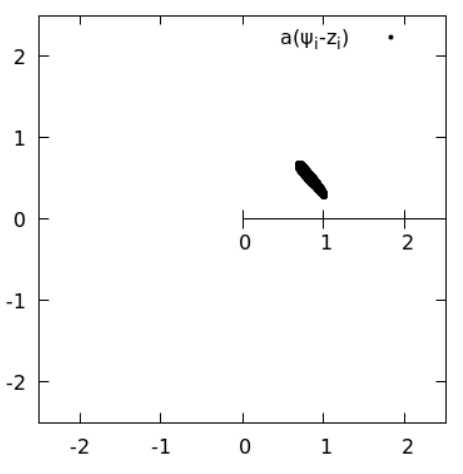

$\mathrm{t}=9$

Fig. 14. The regime of strong synchronization of nonlinear oscillators.

The behavior of the oscillators in the phase plane at different points in time

\section{CONCLUSIONS}

Thus, we can distinguish two kinds of behavior of the system.

The system of excited oscillators with random phases ensures effective generation of waves, the initial amplitude of which was quite small. That is, the first, the "generation" mode is not effective.

So, consider the second, the "synchronization" mode of oscillators by a wave of finite amplitude. If the initial wave amplitude is large enough, it is able to effectively exchange energy with the system of oscillators with small amplitude. In this case, the phase lock of the oscillators (together with the phase of the wave) would be nonstrict, i.e., the phases differences of the oscillators will vary. However, their spread will remain limited, though noticeable. It is important that almost all of the oscillators move from the absorption mode to the radiation mode (at the frequency of the wave) due to a sharp jump of wave's phase. This jump occurs because of the significant reduction of the wave's amplitude.

A powerful wave can lead to a noticeable and efficient synchronization of phases (phase lock) of oscillators, which had small initial amplitudes and random phases. The exchange of energy between the system of linear oscillators and the field is significant, which is typical for the so-called pendulum oscillations. It is very effective, almost all wave energy converted to the energy of oscillatory motion, while the variation of the phases of oscillators is very small. The main wave's phase jump which occurs when the wave's amplitude significantly decreases sharply translates the system from the absorption to the radiation mode.

Introduction of the relativity effects leads to a nonlinear term in the equations for the phases of oscillators. This nonlinearity leads to a phase mismatch that reduces the efficiency of transmission of wave energy to the oscillators. The minimum wave amplitude, in this case, is not so small, which leads to a smoother "transfer" of the captured phases of 
oscillators from the absorption zone to the zone of radiation at the wave's frequency. However, even a significant nonlinearity of this kind does not lead to strong changes in the nature of pendulum oscillations in the regime of synchronization by a large field.

\section{REFERENCES}

1. Arnold V.I. Matematicheskie metody klassicheskoy mehanini [Mathematical Methods of Classical Mechanics.]. - M.: Nauka, 1979. - 432p. (in Russian)

2. Pikovsky A.S., Rosenblum M.G., Kurts Yu. Sinhronizacia. Fundamentaloe nelineinoe yavlenie [Synchronization. A fundamental nonlinear phenomenon.]. - M.: Tehnosphera, 2003. - 508p. (in Russian)

3. Osipov G.V., Polovinkin A.V. Sinhronizacia vneshnim periodichezkim vozdeistviem [Synchronization with external periodic impact]. - N.Novgorod: NNGU, 2005. - 78p. (in Russian)

4. Anishenko B.S., Astahov V.V., Vadivasova T.E., Strelkova G.I., Sinhronizacia reguliarnyh, hartichezkih i stohasticheskih kolebaniy [Synchronization of regular, chaotic and stochastic oscillations.]. - M.-Izhevsk: Institut komputernyh issledovaniy, 2008. - 144 p. (in Russian)

5. Kapitsa P.L. Mayatnik s vibriruyushchim podvesom [Pendulum with vibrating suspension] // Uspekhi Fizicheskikh Nauk. 1951. - Vol.44. - P.7 - 20. (in Russian)

6. Chason R. Suppresion of chaos by selective resonant parametric perturbations // Phys. Rev. - 1995. - Vol. E51. - P.761-76.

7. Il'inskii Yu.A., Maslova N.S. Classical analog of superradiance in a system of interacting nonlinear oscillators // Zh. Eksp. Teor. Fiz. - 1988. - Vol.91. - No.1. - P.171-174. 